\title{
Partographic analysis of labour by modified who partograph in primigravidae: a prospective observational study
}

\author{
Kavitha G. Pujar*, Shruthi V. Salian, Sunanda R. Kulkarni
}

Department of Obstetrics \& Gynaecology, Chinmaya Mission Hospital, Indiranagar, Bangalore, Karnataka, India

Received: 05 November 2015

Accepted: 12 December 2015

\author{
*Correspondence: \\ Dr. Kavitha G. Pujar, \\ E-mail: drkavithapujar@gmail.com
}

Copyright: ( ) the author(s), publisher and licensee Medip Academy. This is an open-access article distributed under the terms of the Creative Commons Attribution Non-Commercial License, which permits unrestricted non-commercial use, distribution, and reproduction in any medium, provided the original work is properly cited.

\begin{abstract}
Background: The objective of this study was to assess the role of partogram in the analysis of outcome of spontaneous labour in primigravidae at term with singleton pregnancy with vertex presentation.

Methods: This prospective observational study was carried out in Chinmaya Mission Hospital, Bangalore over a period of 2 years, from February 2013 to March 2015. A partographic analysis of labour was done in 300 primigravidae using modified WHO partogram. The study population was divided into 3 groups, group I- cervical dilatation and descent curve falling to the left of alert line. Group II- cervical dilatation and descent curve falling to the right of alert line. Group III cervical dilatation and descent curve falling to the right of action line. Partographic analysis was done and maternal and neonatal outcomes were studied in these groups.

Results: In this study, 300 primigravidae in labour were analysed. Of these 282(94\%) women belonged to group I, $18(6 \%)$ belonged to group II. There were no cases in group III. Mean durations of active phases of labour were 4.75 hrs and $7.74 \mathrm{hrs}$ in group I and II. In group I, 275(98\%) women delivered vaginally, 7(2\%) underwent LSCS and 96 $(34 \%)$ had instrumental deliveries. In group II, 14(78\%) women delivered vaginally, 4(23\%) had instrumental delivery and 4(22\%) underwent LSCS.

Conclusions: The WHO modified partogram is highly effective in reducing both maternal and neonatal morbidity. It aids in assessing the progress of labour and to identify when intervention is necessary.
\end{abstract}

Keywords: Partogram, Spontaneous labour, Alert line, Action line

\section{INTRODUCTION}

A partogram is a graphical presentation of a woman's progress of labour. The partogram was designed by Philpott in 1971 in Harare, Zimbabwe. ${ }^{1}$ The partogram was endorsed and modified by the World Health Organisation (WHO) between 1990\& 2000 to monitor the fetal and maternal wellbeing during the active stage of labour.

Partogram is an important tool for managing labour. This is through enabling midwives, nurses and doctors to record their examination findings on a standardized form, which generates a pictorial overview of labour progress and maternal and fetal condition, which allows for early identification and diagnosis of pathological labour. ${ }^{2}$

Its use is critical in preventing maternal and perinatal morbidity and mortality and therefore has applicability in developed and developing world settings. Partograms have three distinct sections where observations related to maternal condition, fetal condition and labour progress are recorded. Cochrane database review done in 2009 has recommended the use of partogram curve in developing countries because of poor access to health care resources. 
Hence it is a useful tool in making early decisions to transfer patient to higher centre when labour is not progressing normally hence it is used in peripheries. The crucial factor in active management of labour is the timing of interventions such as amniotomy, augmentation with oxytocin, caesarean section or transfer to higher centre. Partogram is a useful tool for timing such interventions. ${ }^{3}$

The objective of this study was to assess the role of partogram in the analysis of outcome of spontaneous labour in primigravidae at term with singleton pregnancy with vertex presentation.

\section{METHODS}

A prospective study was carried out in labour room at Chinmaya Mission Hospital, Bangalore from February 2013 to March 2015. During this study period, 300 primigravidae who fulfilled the inclusion criteria were included in the study.

\section{Inclusion criteria}

- Primigravida

- Singleton pregnancy

- Term( after 37 completed weeks)

- Spontaneous labour

- Cephalic presentation

\section{Exclusion criteria}

- Severe PIH

- Severe anaemia

- Uncontrolled diabetes

- Major degrees of CPD

- Contracted pelvis

- Malpresentation

- Post caesarean pregnancy

- Multiple pregnancy

- Antepartum haemorrhage

- Intrauterine death.

The primigravidae fulfilling all inclusion criteria were studied using WHO modified partogram. The labour details were plotted using WHO modified partogram as soon as the woman enters into active phase of labour i.e $4 \mathrm{~cm}$ dilatation with good uterine contractions. Careful monitoring of progress of labour was done on a WHO modified partogram which displayed all the features of labour on a single sheet of paper. Monitoring of maternal and fetal conditions were carried out and plotted on the partogram.

Patient was adequately hydrated by oral or intravenous route. Amniotomy was done at $4 \mathrm{~cm}$ dilatation, oxytocin augmentation was done if uterine inertia was noted. Decision for LSCS or instrumental delivery taken whenever indicated. Active management of third stage of labour done in all groups. Baby's APGAR noted at 5 minutes. The study group was divided as mentioned above and the outcome of labour management was studied in respect to each group. The statistical analysis was performed by STATA 11.2 (college station TX USA). Standard statistical tests (students $\mathrm{T}$ test, chi square test) were used where ever applicable.

\section{RESULTS}

300 primigravidae in active labour were analysed using WHO modified partogram. Group I consisted of $282(94 \%)$ primigravidae, $18(6 \%)$ belonged to group II and no cases in group III. In the study majority of them belonged to 21-25 years age group i.e. $129(46 \%)$ in group I and $11(61 \%)$ in group II (Table 1$)$.

Table 1: Age distribution in both the groups.

\begin{tabular}{|c|c|c|c|c|}
\hline & Group I & Group II & Total & P-Value \\
\hline$\leq 20$ & $45(16 \%)$ & $5(28 \%)$ & 50 & \multirow{5}{*}{0.128} \\
\hline $21-25$ & $129(46 \%)$ & $11(61 \%)$ & 140 & \\
\hline $26-30$ & $95(34 \%)$ & $2(11 \%)$ & 97 & \\
\hline$\geq 30$ & $13(5 \%)$ & 0 & 13 & \\
\hline Total & 282 & 18 & 300 & \\
\hline
\end{tabular}

The mean duration of active phase of labour in group I was 4.75 hours and 7.74 hours in group II (Table 2). The mean duration of active phase of labour is the main factor that is prolonged, as the curve falls to the right of the alert and action line and the difference is statistically significant ( $\mathrm{p}$ value $<0.001$ ). The mean duration of second stage of labour in group $\mathrm{I}$ is 45.8 minutes and group II 85 minutes (Table 3).

Table 2: Mean Duration of Active Phase (hours) of labour.

\begin{tabular}{|lllll|}
\hline & Group 1 & Group 2 & Overall & $\begin{array}{l}\text { P- } \\
\text { value }\end{array}$ \\
\cline { 1 - 4 } $\begin{array}{l}\text { Mean } \\
\pm \text { SD }\end{array}$ & $4.75 \pm 0.98$ & $7.74 \pm 1.02$ & $4.93 \pm 1.21$ & $<0.001$ \\
\hline Range & $3.17-8.92$ & $6.0-9.33$ & $3.17-9.33$ & \\
\hline
\end{tabular}

Table 3: Mean Duration of Second stage (min) of labour.

\begin{tabular}{|c|c|c|c|c|}
\hline & Group 1 & Group 2 & Overall & $\begin{array}{l}\text { P- } \\
\text { Value }\end{array}$ \\
\hline $\begin{array}{l}\text { Mean } \pm \\
\text { SD }\end{array}$ & $\begin{array}{l}45.58 \pm \\
3.10\end{array}$ & $85 \pm 0.42$ & $43.56 \pm 9.21$ & \multirow[t]{2}{*}{$<0.001$} \\
\hline Range & $41-56$ & $0.67-1.83$ & $4.5-56$ & \\
\hline
\end{tabular}

Oxytocin augmentation was done in $36(13 \%)$ in group I and in $13(72 \%)$ in group II. It was statistically significant ( $\mathrm{p}$ value $<0.001)$ (Table 4).

Table 4: Augmentation of labour with oxytocin. 


\begin{tabular}{|c|c|c|c|c|}
\hline & Group I & Group II & Total & P-Value \\
\hline Yes & $36(13 \%)$ & $13(72 \%)$ & $49(16 \%)$ & \multirow{3}{*}{$<0.001$} \\
\hline No & $246(87 \%)$ & $5(28 \%)$ & $251(84 \%)$ & \\
\hline Total & 282 & 18 & 300 & \\
\hline
\end{tabular}

As shown in Table 5\&6, in group I, 179 (63\%) delivered normally, 96 (34\%) had an instrumental delivery and $7(2 \%)$ underwent LSCS. In group I, 275 (98\%) had a vaginal delivery (normal and instrumental). In group II, $10(55 \%)$ delivered normally, $4(23 \%)$ had an instrumental delivery and 4 (22\%) underwent LSCS. In group II $14(78 \%)$ had a vaginal delivery (normal and instrumental). There is a statistically significant difference in mode of delivery in group I and II ( $\mathrm{p}$ value $<0.001)$. In our study, indications for LSCS in group I was fetal distress (4), CPD (2), arrest of descent (1). In group II the indications for LSCS was arrest of descent (2), protracted dilatation (1) and fetal distress (1).

Table 5: Comparison of mode of delivery amongst groups.

\begin{tabular}{|c|c|c|c|c|}
\hline & Group I & Group II & Total & P Value \\
\hline $\begin{array}{l}\text { Normal+ } \\
\text { Instrumental }\end{array}$ & $\begin{array}{l}275 \\
(98 \%)\end{array}$ & $\begin{array}{l}14 \\
(78 \%)\end{array}$ & $\begin{array}{l}289 \\
(96 \%)\end{array}$ & \multirow[t]{3}{*}{$<0.001$} \\
\hline LSCS & $7(2 \%)$ & $4(22 \%)$ & $11(4 \%)$ & \\
\hline Total & 282 & 18 & 300 & \\
\hline
\end{tabular}

Table 6: Indication for LSCS amongst groups.

\begin{tabular}{|llll|}
\hline Arrest of descent & 1 & 2 & 3 \\
\hline CPD & 2 & 0 & 2 \\
\hline Fetal distress & 4 & 1 & 5 \\
\hline $\begin{array}{l}\text { Protracted } \\
\text { dilatation }\end{array}$ & 0 & 1 & 1 \\
\hline Total & 7 & 4 & 11 \\
\hline
\end{tabular}

The indications for instrumental delivery in our study was found to be fetal distress in 54 and failure of secondary forces in 42 cases in group I. In group II, out of 4 cases, 3 had an instrumental delivery in view of failure of secondary forces and 1 for fetal distress (Table 7).

Table 7: Indication for Instrumental delivery amongst groups.

\begin{tabular}{|lll|l|}
\hline & Group I & Group II & Total \\
\hline Fetal distress & 54 & 1 & 55 \\
\hline $\begin{array}{l}\text { Failure of } \\
\text { secondary forces }\end{array}$ & 42 & 3 & 45 \\
\hline Total & 96 & 4 & 100 \\
\hline
\end{tabular}

The APGAR score at 5 min, was between 4-7 in $10(4 \%)$ of cases in group I and 8-10 in 273(96\%) babies. In group II, the APGAR score at 5 min was $4-7$ in $1(6 \%)$ and $8-10$ in $17(94 \%)$ of babies. This was not statistically significant. NICU admissions was seen in 3(1\%) babies in group I and 1 (5\%) baby in group II. Majority babies recovered completely before discharge from hospital.

Table 8: Apgar score (at 5min).

\begin{tabular}{|lllll|}
\hline & Group I & Group II & Total & P Value \\
\cline { 1 - 4 } $4-7$ & $10(4 \%)$ & $1(6 \%)$ & $11(4 \%)$ & \\
\cline { 1 - 4 } 0 & \multirow{2}{*}{0.658} \\
\cline { 1 - 4 } Total & $282(96 \%)$ & $17(94 \%)$ & $289(96 \%)$ & \\
\hline
\end{tabular}

There was no perinatal or maternal mortality noted in our study.

\section{DISCUSSION}

Although in majority of cases, labour is a natural phenomenon occurring spontaneously, a few tend to become dystocic and result in prolonged labour. Hence it is essential to detect them and deliver by appropriate intervention. ${ }^{4}$ Partogram is a simple and efficient method of preventing prolonged labour and its complications, especially in developing countries. The partogram initially introduced by Philpott and endorsed by WHO is a simple and accurate instrument for early recognition of abnormal labour.

Active management of labour advocates early recognition of non-progressive labour. This can be done by using a partogram or graphical depiction of a labour curve. Partogram is useful in making early decision to transfer the patient to higher centre when labour is not progressing normally; therefore it is used in peripheries.

In the prospective study conducted at Chinmaya Mission Hospital, 300 primigravidae with spontaneous labour were analysed by modified WHO partogram and its effects on maternal and neonatal outcome were studied. In our study majority of them belonged to 21-25yrs age group.

The mean duration of active phase of labour was 4.75 hours in group I and 7.74 hours in group II. Duration of active phase of labour is the main indicator for delayed progress of labour. These rates are comparable with those of the study conducted by Daftary and Mhatre et al. ${ }^{5}$ and Lakshmidevi et al. ${ }^{6}$ The mean duration of second stage of labour in our study was $45.58 \mathrm{~min}$ in group I and 85 min in group II. It was comparable with studies done by Zhang et al. ${ }^{6}$ and Lakshmidevi et al. ${ }^{6}$ Labour was accelerated with oxytocin in majority of cases in group II i.e $13(72 \%)$ than in group I.

The mode of delivery was affected as the curve was shifted to the right. In group I ,98\% delivered vaginally (normal + instrumental). Whereas in group II 14 (78\%) had a vaginal delivery. Increase in incidence of LSCS was seen in group II, $4(22 \%)$ as compared to group I $7(2 \%)$. However in our study the rate of instrumental delivery was more in both the groups i.e. group I, $34 \%$ 
and group II, 23\%. In our study only outlet forceps and outlet vacuum applications were done. The commonest indication for instrumental delivery was failure of secondary forces for which outlet forceps and vacuum was applied. The similar results were obtained by Lakshmidevi et al. ${ }^{6}$ and Javed et al. ${ }^{8}$ However we did not have any patients belonging to group III.

In group I, the main indicator for LSCS was fetal distress and CPD and in group II the commonest indication was arrest of descent. This was comparable with the studies done by Lakshmidevi et al. ${ }^{6}$ and Kavya Mahesh et al. ${ }^{4}$

The APGAR score at $5 \mathrm{~min}$ in both the groups in our study was not statistically significant. 4 babies out of 300 required NICU admission which was not statistically significant.

\section{CONCLUSIONS}

The WHO modified partogram is highly effective in reducing both maternal and neonatal morbidity. It aids in assessing the progress of labour and to identify when intervention is necessary. It is effective in preventing prolonged labour, obstructed labour, reducing operative intervention and improving neonatal outcome. In this study, mean duration of active phase of labour increased as the partographic curve fell to the right of alert and action line. Increased rates of LSCS were observed in group II. An overall increase in instrumental deliveries was seen in both groups. APGAR score and NICU admissions in both groups were similar and not statistically significant.

The following conclusions can be drawn from our study:

- Partogram is useful in identification of abnormal and prolonged labour.

- Helps in making an early decision in for timing the necessary intervention or for transfer to higher centre.

- Duration of active phase of labour is the main indicator for delayed progress of labour which in turn reflects the mode of delivery and need for augmentation of labour.

\section{ACKNOWLEDGEMENTS}

We acknowledge Dr. P. E Sarkar, former DNB Co ordinator at $\mathrm{CMH}$ hospital for his continuous support and guidance throughout the study. We also acknowledge all our post graduate students who were involved in the study

Funding: No funding sources

Conflict of interest: None declared

Ethical approval: The study was approved by the Institutional Ethics Committee

\section{REFERENCES}

1. Philpott RH. Graphic records in labour. Br Med J. 1972;4:163.

2. Yisma E, Dessalegn B, Astatkie A, Fesseha N. Knowledge and utilization of partograph among obstetric care givers in public health institutions of Addis Ababa, Ethiopia. BMC Pregnancy and Childbirth. 2013;13:17.

3. Lavender T, Hart A, Smyth RM. Effect of partogram use on outcomes for women in spontaneous labour at term. Cochrane Database Syst Rev. 2008;8(4):CD005461.

4. Penumadu KM, Hariharan C. Role of partogram in the management of spontaneous labour in primigravida and multigravida. Int $\mathrm{J}$ Reprod Contracept Obstet Gynecol. 2014;3(4):1043-9.

5. Daftary SN, Mhatre PN. Cervicograph in the management of labour in primigravidae. J Obstet Gynecol. 1977;27:687-91.

6. Lakshmidevi, Muralidhar, Malini KV, Shetty VH. Partographic analysis of spontaneous labour at term in primigravida. $\mathrm{J}$ Obstet Gynecol India. 2012;62(6):635-40.

7. Zhang J, Troendle JF, Yancey MK. Reassuring the labour curves in nulliparous woman. MosbyYearbook Inc. 2002;187(4):824-8.

8. Javed I, Bhutta S, Shoaib T. Role of partogram in preventing prolonged labour. J Pak Med Assoc. 2007;57(8):408-11.

Cite this article as: Pujar KG, Salian SV, Kulkarni SR. Partographic analysis of labour by modified who partograph in primigravidae: a prospective observational study. Int J Reprod Contracept Obstet Gynecol 2016;5:166-9. 